\title{
Understanding Word-of-Mouth in Counterfeiting
}

\author{
Meei-Ying Lan ${ }^{1}$, Fangyi Liu ${ }^{1 *}$, Cheng-Hsi Fang ${ }^{2}$, Tom M. Y. Lin ${ }^{1}$ \\ ${ }^{1}$ Department of Business Administration, National Taiwan University of Science and Technology, \\ Taipei, Chinese Taipei \\ ${ }^{2}$ Department of Marketing and Distribution Management, Ching Yun University, Zhongli City, Chinese Taipei \\ Email: *fion@ccms.nkfust.edu.tw
}

Received December 30 ${ }^{\text {th }}, 2011$; revised February $1^{\text {st }}$, 2012; accepted March $2^{\text {nd }}, 2012$

\begin{abstract}
Counterfeiting is a significant and growing problem in both growing and well developed countries. Since the promotion of counterfeits cannot use public media, it is interesting to investigate how people exchange information and finally affect the sales of counterfeit. Although role of word-of-mouth (WOM) has been studied for many years for brand or well known products, limited attention has been given to explore its role in counterfeiting. To further the understanding of this issue, the present study developed a self-report scale measuring consumer motivations for opinion seeking and giving in counterfeiting. We surveyed Indian and Taiwanese customers and found the following results: 1) WOM has significant role in locating counterfeit products; 2) WOM cannot considered as best purchasing driver; 3) Referral marketing does work and people share their opinion among strong tie; 4) The impact of PWOM is generally greater than NWOM; and 5) Most consumer share opinion that it is unethical to purchase counterfeit products. The authors then discuss the implications of this research and offers recommendations for marketers of brand products.
\end{abstract}

Keywords: Counterfeiting; Word-of-Mouth; Tie Strength; Purchase Drivers

\section{Introduction}

Counterfeiting is a significant and growing problem worldwide, occurring both in less and well developed countries. In the USA economy, the cost of counterfeiting is estimated to be up to $\$ 200$ billion per year (Chaudhry et al., 2005). Considering the countries worldwide, almost 5 percent of all products are counterfeit, according to the International Ant counterfeiting Coalition (IACC, 2005) and the International Intellectual Property Institute (IIPI, 2003). The global market for counterfeits today is estimated to exceed $\$ 600$ billion, accounting for approximately $7 \%$ of world trade (World Customs Organization 2004). Counterfeit products didn't use any media advertisement still products can be sold in large quantities. Moreover, counterfeiting has also been linked to the growing global threats of narcotics, weapons, human trafficking, and terrorism (Thomas 2007).

Consumers have a natural instinct to tell others about products they have purchased and services they have used and they usually discuss their likes and dislikes with their friends and family about known brands. Base on researchers have examined the conditions under which consumers are likely to rely on others' opinions to make a purchase decision, word-of-mouth (WOM) is expected to have much more influence, still we cannot find any research that mention any role of WOM on influencing consumer attitudes towards buying these products. Although role of WOM has been studied for many years for brand or well known products, limited attention has been given to explore the role of WOM in counterfeiting. Furthermore, there are other researchers who have worked on the power of word of mouth and its influence on purchase decision (e.g. Bansal \& Voyer, 2000) still there is no research addressing the influence of word

*Corresponding author. of mouth in the context of purchasing counterfeit products.

This research on the role of WOM in counterfeiting is required for five reasons. First, counterfeits do not use any media advertisement. So, how do people locate counterfeits? Does WOM have any significant role on locating counterfeits? Second, WOM is a powerful influence of consumer behavior. Do people recommend buying counterfeit products? Third, WOM is often the major reason for any product choice, but we do not yet understand how Positive WOM and Negative WOM contribute to the influence on buying counterfeits. Fourth, once product is counterfeit, what kind of WOM (positive/negative) has more powerful impact on purchase probability? Fifth, what factors can influence consumer evaluation of non-deceptive counterfeits? In the remainder of this paper, the methodology adopted for this investigation will be described. This will be followed by a presentation of the results of the investigation. The paper will conclude with a discussion of the outcomes of the survey.

\section{Literature Review}

\section{Understanding Counterfeiting}

Counterfeiting is a process which involves the production of copies which are identically packaged, including trademarks and labeling copies so as to seem to a consumer to be the genuine article (Key, 1990). Any unauthorized manufacturing of goods whose special characteristics are protected as intellectual property rights (trademarks, patents and copyrights) constitutes product counterfeiting (Cordell et al., 1996; Chaudhry et al., 2005). Counterfeit goods are illegal, low-priced, and often lower-quality replicas of products that typically possess high brand value (Lai \& Zaichkowsky, 1999).

Counterfeits are available quite extensively, and with a num- 
ber of forms of deception. For some counterfeit brands, consumers do not know that they are not genuine when they are purchased called deceptive counterfeits while for others, consumers are fully aware that they are buying non-genuine brands known as non-deceptive counterfeits (Grossman \& Shapiro, 1988). The quality of counterfeits varies according to product. Some counterfeit products are so good that even the brand owners are not able to distinguish them from genuine products without the help of laboratory tests, while others are very poor and easily distinguished.

\section{Attitude towards Counterfeits}

Consumer intentions to buy counterfeited products are dependent on the attitudes they have toward counterfeits, which in turn are more influenced by perceived risk, whether consumers have bought a counterfeit before, subjective norm, integrity, price-quality inference and personal gratification (Ashdown et al., 2011; Maltos et al., 2007). Consumers' preferences for a counterfeit brand and the subsequent negative change in their preferences for the real brand are greater when their luxury brand attitudes serve a social-adjustive rather than a valueexpressive function (Wilcox et al, 2009). When consumers have a social-adjustive attitude toward a product, they are motivated to consume it to gain approval in social situations. Conversely, attitudes serving a value expressive function (i.e., value-expressive attitudes) help people communicate their central beliefs, attitudes, and values to others (Katz, 1960). When consumers hold a value expressive attitude toward a product, they are motivated to consume it as a form of self-expression (Snyder \& De Bono, 1985). Social-adjustive attitudes toward luxury brands will motivate consumers to consume such products for form- or image-related reasons, whereas value expressive attitudes toward luxury brands will motivate them to consume such products for product function or, more specifically, qualityrelated reasons. Thus, compared with value-expressive attitudes, social-adjustive attitudes toward luxury brands should be associated with a greater preference for counterfeit brands because these are designed to look like luxury brands (i.e., high resemblance in terms of product form) but are typically associated with lesser quality (i.e., low resemblance in terms of product function).

\section{Factors of Purchasing Counterfeits}

Previous research on purchasing counterfeits has connected with many factors, which Eisend and Schuchert-Guler (2006) classify into four categories. The first category labeled "person" includes demographic and psychographic variables, as well as attitudes toward counterfeiting. For example, consumers who purchase counterfeit products are of lower social status (Bloch et al., 1993; Peters \& Rowat, 2011) and have more favorable attitudes toward counterfeiting (Penz \& Stottinger, 2005). Research linking consumers' beliefs about counterfeits to their purchase behavior (e.g., Gentry et al., 2006; Rabaglietti et al., 2011) also falls under this category. The second category focuses on aspects of the product, such as price, uniqueness, and availability. Not surprisingly, consumers' likelihood of buying a counterfeit brand is inversely related to the price of the genuine brand. The third and fourth categories refer to the social and cultural context in which the counterfeit purchase decision is made, ranging from cultural norms (Chang et al, 2011; Lai \&
Zaichkowsky, 1999) to the shopping environment (Leisen \& Nill, 2001). For example, consumers are likely to purchase a counterfeit brand when they react more favorably to the shopping environment. Most of the authors who had written about counterfeiting focused on above mentioned factors.

\section{Understanding Word-of-Mouth}

WOM is defined as oral, person-to-person communication between a receiver and a communicator whom the receiver perceives as non-commercial, regarding a brand, product or service (Arndt, 1967). WOM communications is defined as informal communications directed at other consumers about the ownership, usage, or characteristics of particular goods and services and/or their sellers (Westbrook, 1987). The exchange of opinions among people about products and services has been widely researched during recent years.

From a marketing perspective, WOM can be either positive or negative. Positive WOM occurs when good news testimonials and endorsements desired by the company are uttered. Negative WOM is the mirror image (Buttle, 1998). It has often been reported that WOM has a significant influence on consumers' decisions to adopt a new product when WOM is positive (Rogers, 2003; Sheth, 1971) and to switch from the product or brand when receiving negative information or rumors (Bone, 1992).

\section{Impact of WOM}

WOM has been shown to influence a variety of conditions: awareness, expectations, perceptions, attitudes, behavioral intentions and behavior (Buttle, 1998) and WOM was more important than advertising in raising awareness of an innovation and in securing the decision to try the product (Sheth, 1971). Day (1971) inferred that this was due to source reliability and the flexibility of interpersonal communication. He computed that WOM was nine times as effective as advertising at converting unfavorable or neutral predispositions into positive attitudes.

WOM has a more emphatic influence on the purchasing decision than other sources of influence (Mangold's, 1987). This is perhaps because personal sources are viewed as more trustworthy (Murray, 1991). In the industrial purchasing context, WOM influences expectations and perceptions during the information search phase of the buying process and influences attitude during the pre-choice evaluation of alternative service providers (Lynn, 1987; Stock \& Zinsner, 1987; Woodside et al., 1992). The influence of WOM on expectations has been reported that WOM communication have strongest impact on quality expectation (Webster, 1991; Zeithaml et al., 1993).

\section{Inference of Literature Review}

Based on Buttle's research (Buttle 1998), we would expect that WOM is more powerful than advertising. This might be one of the reasons to sell counterfeits without using any advertizing media. But in counterfeit case, WOM is expected to play significant role, still no attempts have been taken in this field. Wilcox et al. (2009) provided convergent evidence that consumers' desire for counterfeit brands rests on the extent to which such brands fulfill the social goals guiding their luxury brand preferences. Although he provided some evidence that influence consumer intention to purchase counterfeit products 
but he didn't mention any evidence of the role of WOM on influencing consumer desire.

Even if Wilcox et al. (2009) found one of the main reason (i.e. social-adjustive ) for buying counterfeit products which shows that consumer knows very well that the product is counterfeit and still buy it to adjust in the society. In order to adjust in the society one must feel comfortable of using the products. If counterfeit purchase is for social-adjustive purpose they will share their opinion in the society. Wilcox et al. didn't mention anything about feedbacks or opinion sharing among counterfeit consumers.

The earliest study on the effectiveness of WOM was survey based (Katz \& Lazarsfeld, 1955) and was followed by more than 70 marketing studies, most of them also inferring WOM from self-reports in surveys (Godes \& Mayzlin, 2004). Researchers have examined the conditions under which consumers are likely to rely on others' opinions to make a purchase decision, the motivations for different people to spread the word about a product, and the variation in strength of people's influence on their peers in WOM communications (Fang et al., 2011). Moreover, customers who self-report being acquired through WOM add more long-term value to the firm than customers acquired through traditional marketing channels (Villanueva et al., 2008). Counterfeiting firms do not acquire any traditional marketing channel. Most of the information is expected to pass through WOM. If the research views are true then consumers of counterfeit products should have long-term value to the counterfeiting firms.

All the PWOM and NWOM research that has been discussed above are either focused on purchase of brand or well known products. Once the product is counterfeit, the impact of PWOM and NWOM may have different result. We will also try to find the impact of PWOM and NWOM in the context.

\section{Methods}

There could be many methods to understand the role of WOM on counterfeit products. One method is to measure Internet postings about brands and their subsequent sales performance (e.g., Godes \& Mayzlin, 2004). East, Hammond and Lomax (2008) explained that there is problem with this method because there may be little correspondence between the content of consumer-generated media and face-to-face advice. One is not necessarily typical of the other, and the large amount of face-to-face advice is likely to be the dominant influence on consumption. A second method is to use laboratory experiments to investigate the response to information on familiar brands. This method is not suitable once we use counterfeit brand because the views on counterfeit products may vary dramatically based on people culture, income level and society. Other techniques that may be used include role-play experiments and surveys. Since, there are many methods available, author found that survey is the best method that can explain the role of WOM in counterfeiting. By using survey method we can understand the power of WOM in counterfeiting as well as the impact of positive or negative word of mouth on counterfeits buying intention. This paper is preceded by reviews of relevant research and followed by a discussion of findings.

The study was conducted in India and Taiwan. Asia is witnessing a spectacular rise in prosperity and a scurry among luxury fashion brands to enter or expand in these markets (Commuri 2009). For example, India stands second only to
Singapore in the rise of its number of millionaires. Brands such as Brioni, Chanel, Escada, Fendi, Louis Vuitton, Valentino, Versace, and iphones, have all recently entered the Indian market, and others are reported to be actively considering such a move. At the same time, fashion brands encounter some of their worst abuse in Asia (Ibison, 2006). Both India and Taiwan have long histories of trafficking in counterfeits. The questionnaire were first developed in English for India and then translated into Chinese for Taiwan. There were 75 questionnaires from India and 1 questionnaire from Taiwan that was unusable and eliminated. Counterfeit mobile phone (for India) and counterfeit bag (for Taiwan) is used as a product category for this study. This choice was made because these products are widely available in counterfeit form in both countries and was perceived to be a product that consumers buy after some thoughts.

Questionnaires were delivered by hand as well as through email without using any incentives. It covered a range of issues, and the relevant questions are shown in Appendix A (English Version) and Appendix B (Chinese Version). The questionnaires were basically categorized into six parts. In the first part, the respondents were asked whether they know any place to buy counterfeit products. If yes, we would like to know whether WOM has any significant role in locating counterfeit products. In the second part, the responded were asked to state their opinion and select reasons behind buying counterfeit products. In third and fourth part they were asked if they had received positive and negative advice in the last one year about counterfeit products. Whether they had received PWOM/NWOM or not they were asked to show their degree of change in their prospective of buying counterfeits before and after they receive PWOM/NWOM. The fifth part of the questionnaire was built to understand the attitude of the people towards counterfeit. It will make us understand the moral issues. The last and sixth part describes gender, age, education and income level of the respondent that may have some relevant relationship towards attitude and purchase of counterfeit after receiving WOM.

The instrument adopted in the second and fifth part of the questionnaire comprising Likert-type five item scales with endanchors $(1=$ strongly disagree, 5 = strongly agree). The other questions in part third and fourth allowed to establish: 1) how strongly expressed the advice was; 2) whether the communicator was close to or distant from the receiver; 3) whether the advice was about the counterfeits; 4) whether the advice was sought or not; and 5) how much advice on the category was given by the respondent. We also noted age and gender and income. All statistical analyses were conducted using SPSS version 19 (SPSS Inc, Chicago, Ill). Results were considered statistically significant if the two-tailed $\mathrm{P}$ value was $<0.05$.

\section{Results}

\section{Role of WOM in Locating Counterfeits}

WOM provides the opportunity to products to share information in setting direct attention. Out of 170 valid respondent, 99 (58\%) claimed that they have never bought counterfeits while 71 (42\%) admitted that they have bought counterfeit products.

Table 1 shows the results on sources of information in finding counterfeits location. 70.6\% respondent said that they know the place because they had heard it from their friends or family. This shows that WOM is the main source of locating counterfeit products. It does not require any media channel, the infor- 
Table 1.

Sources of information in finding location.

\begin{tabular}{ccccc}
\hline Source & $\begin{array}{c}\text { Frequency } \\
(\mathrm{n}=170)\end{array}$ & Percentage & $\begin{array}{c}\text { India } \\
(\mathrm{n}=96)\end{array}$ & $\begin{array}{c}\text { Taiwan } \\
(\mathrm{n}=74)\end{array}$ \\
\hline Friend/Family & 84 & $70.6 \%$ & $83.6 \%$ & $50.0 \%$ \\
Night market/Footpath & 50 & $42.0 \%$ & $23.3 \%$ & $71.7 \%$ \\
Internet & 46 & $38.7 \%$ & $38.4 \%$ & $39.1 \%$ \\
News paper/Magazine & 12 & $10.1 \%$ & $11.0 \%$ & $8.7 \%$ \\
Leaflet & 10 & $8.4 \%$ & $9.6 \%$ & $6.5 \%$ \\
Television & 9 & $7.6 \%$ & $5.5 \%$ & $10.9 \%$ \\
Others & 2 & $1.7 \%$ & $0.0 \%$ & $4.3 \%$ \\
\hline
\end{tabular}

mation passes from friends or family is enough to locate the market place. The other sources remain very limited to offer information to locate counterfeits. In India, 54.3\% people accepted that they had bought the counterfeit products from general shops while in Taiwan; most of the respondent (57.9\%) believe that hot place to buy these products is night market or footpath. Our survey shows that general shops in India and night markets in Taiwan are the major places where people go to buy counterfeit products. Overall result shows that WOM is the main channel of passing information to locate counterfeit products.

\section{Counterfeiting Drivers}

Table 2 shows that the most important driver of buying non deceptive counterfeit is the price difference between original brand and the counterfeit brand. We found products fashionable as the second important driver of buying counterfeits. This support Wilcox et al. (2009) research findings that consumers' preferences for a counterfeit brand are greater when it serve social-adjustive function rather than value-expressive function. Once products are fashionable, it motivates consumers to consume such products for form or image related reasons. Although products qualities are low but they are designed to looks like original brand. Friends or family recommendations for purchasing non-deceptive counterfeit brands cannot not considered as the main driver. It seems that people already has clear concept about counterfeits quality and don't want to get impressed by WOM. In other words WOM does not play as active as price difference between counterfeits and original brand to influence consumers. The drivers of buying non deceptive counterfeit products are shown with their mean in Table 2.

\section{Information Channel and Tie Strength}

There were $74.1 \%$ respondents who agreed that they had received PWOM while $74.7 \%$ had received NWOM for more than once in a year. This result provides answer to our second question (whether people recommend buying non-deceptive counterfeits?) and proved that referral marketing does work for counterfeit products. Figure 1 also shows that most receivers do not seek for the information while it is given without seeking.

Because referral behavior is a social phenomenon, properties of social relations are likely to have a crucial role in its occurrence. A consumer's social relations with others typically include a spectrum of ties from strong (very familiar) to weak (not familiar at all).Most of customer who received either PWOM or NWOM on counterfeits shows strong tie (PWOM strong tie $=75 \%$, NWOM strong tie $=59.8 \%$ ). It shows that customer who received information was passed from their very close relatives or friends. Moreover, strong ties do not show any relevant relation with WOM intensity on counterfeits recommendation.

Table 2.

Counterfeiting drivers.

\begin{tabular}{|c|c|c|c|c|c|c|}
\hline \multicolumn{6}{|c|}{ Counterfeiting drivers } & \multirow{2}{*}{ Mean } \\
\hline Driver & Strongly disagree (1) & Disagree (2) & Neutral (3) & Agree (4) & Strongly Agree (5) & \\
\hline Fascinating with original brand & 8.8 & 14.7 & 25.9 & 43.5 & 7.1 & 3.25 \\
\hline Good previous experience & 5.9 & 17.2 & 34.9 & 34.9 & 7.1 & 3.2 \\
\hline Decorate social position & 10.6 & 24.7 & 13.5 & 40.6 & 10.6 & 3.16 \\
\hline Friends/family recommendation & 7.1 & 25.3 & 27.6 & 34.7 & 5.3 & 3.06 \\
\hline Quality is not bad & 4.7 & 32.4 & 28.8 & 30.6 & 3.5 & 2.96 \\
\hline Good product design & 9.4 & 28.2 & 28.8 & 30.6 & 2.9 & 2.89 \\
\hline Fashionable & 20.6 & 27.6 & 10.6 & 37.1 & 4.1 & 2.76 \\
\hline Low price & 27.6 & 27.1 & 4.7 & 25.3 & 15.3 & 2.74 \\
\hline \multirow{2}{*}{ Driver } & \multicolumn{2}{|c|}{ India } & \multicolumn{2}{|c|}{ Taiwan } & \multirow{2}{*}{$\mathrm{t}$} & \multirow{2}{*}{ p-value } \\
\hline & Mean & Std. & Mean & Std. & & \\
\hline Low price & 1.60 & 0.72 & 4.20 & 0.72 & -23.35 & 0.00 \\
\hline Quality is not bad & 2.52 & 0.91 & 3.53 & 0.76 & -7.68 & 0.00 \\
\hline Good previous experience & 3.21 & 1.10 & 3.19 & 0.86 & 0.11 & 0.91 \\
\hline Good product design & 2.71 & 1.09 & 3.14 & 0.91 & -2.77 & 0.01 \\
\hline Fashionable & 2.27 & 1.18 & 3.41 & 1.06 & -6.49 & 0.00 \\
\hline Friends/family recommendation & 3.22 & 1.05 & 2.85 & 1.02 & 2.30 & 0.02 \\
\hline Decorate social position & 3.70 & 1.01 & 2.46 & 1.11 & 7.50 & 0.00 \\
\hline Fascinating with original brand & 3.11 & 1.09 & 3.43 & 1.03 & -1.92 & 0.06 \\
\hline
\end{tabular}




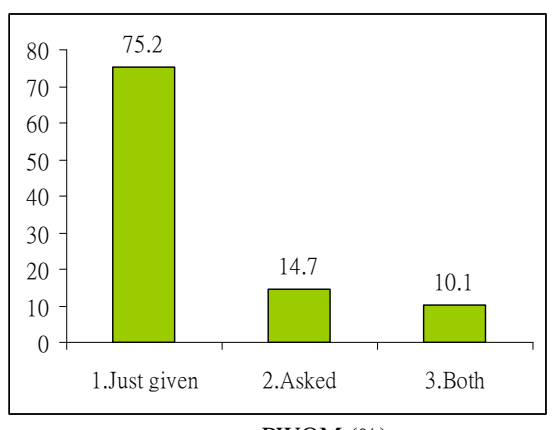

PWOM (\%)

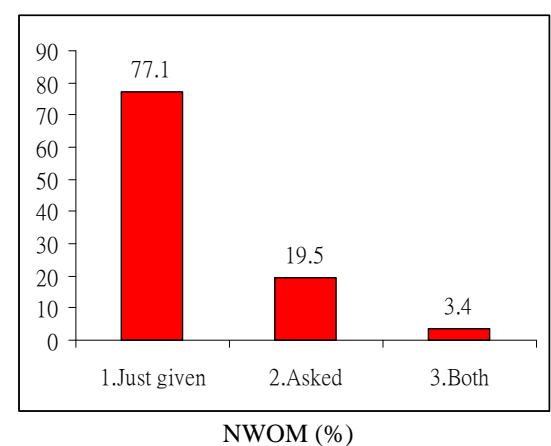

$\operatorname{NWOM}(\%)$

Figure 1.

Information channel (PWOM); Information channel (NWOM).

\section{Impact of PWOM and NWOM}

Tables 3 and $\mathbf{4}$ shows the impact of positive and negative advice in the context of counterfeit products. Mean responses from PWOM and NWOM are shown in the last column of each table.

Difference in the mean shows that PWOM and NWOM has significant role in affecting decision of customer. Mean difference of PWOM which is 0.71 while mean difference of NWOM is 0.34. Since mean difference of PWOM is greater than mean difference of NWOM, we can conclude that PWOM is more effective in changing customer decision to purchase counterfeits. From this result we can also conclude that PWOM has more impact over NWOM for counterfeit goods.

\section{Attitude and Ethical Issues}

Attitude serve several psychological functions, such as helping people organize and structure their environment, attain rewards and avoid punishments and maintain their self-esteem. In the context of counterfeits purchase, consumer evaluation is an important predictor of his/her intention to buy as well as how much agreement about his behavior he/she receives from his/her reference group. Based on our survey, unfair price of the original brand motivates consumer attitude to go for counterfeits. $86.5 \%$ believes that price of original brands are too high. Consumer purchase of a counterfeit is not a criminal act, but greater number of respondent (48.8\%) believes that it is illegal to buy counterfeits while $32.9 \%$ stay with their neutral view and very few respondents (18.2\%) do not think it is an illegal act. Consumers perceiving that their friends/family approve their behavior of buying a counterfeit will have favorable attitude towards counterfeits. Most respondents believe that it is an immoral or unethical act and once they buy these products their friends/family will look down on him. The unfavorable attitudes and strong NWOM toward counterfeits may keep customer away from buying these products.

Comparing India with Taiwan, people in India typically hold a more positive attitude toward counterfeit products. They feel more comfortable on using counterfeit and believe there's no difference between original brand and counterfeit.

\section{Discussion and Implication}

The authors all agree that there is no better advertising than word of mouth. After all, a customer who calls you, following a personal recommendation from a friend or colleague is more likely to buy (Gordon, 2006). By this, it can be concluded that
Table 3.

Decision change (PWOM).

\begin{tabular}{cccccccccc}
\hline \multicolumn{8}{c}{ Decision change } \\
\hline $\begin{array}{c}\text { Very } \\
\text { Low }\end{array}$ & Low & Neutral & High & $\begin{array}{c}\text { Very } \\
\text { High }\end{array}$ & Mean & t & $p$-value \\
\hline $\begin{array}{c}\text { Before } \\
\text { PWOM }\end{array}$ & 22.3 & 36.1 & 35.5 & 4.8 & 1.2 & 2.17 & & \\
$\begin{array}{c}\text { After } \\
\text { PWOM }\end{array}$ & 7.4 & 21.5 & 28.8 & 34.4 & 8.0 & 2.88 & & \\
\hline
\end{tabular}

Table 4.

Decision change (NWOM).

\begin{tabular}{ccccccccc}
\hline \multicolumn{8}{c}{ Decision change } \\
\hline $\begin{array}{l}\text { Very } \\
\text { Low }\end{array}$ & Low & Neutral & High & $\begin{array}{c}\text { Very } \\
\text { High }\end{array}$ & Mean & t & $p$-value \\
\hline $\begin{array}{c}\text { Before } \\
\text { NWOM }\end{array}$ & 19.0 & 21.5 & 48.5 & 9.2 & 1.8 & 2.34 & & \\
$\begin{array}{c}\text { After } \\
\text { NWOM }\end{array}$ & 30.0 & 35.6 & 30.0 & 4.4 & 0 & 2.00 & & \\
\hline
\end{tabular}

this traditional concept of WOM is very effective even today and most probably it will be important in future. In most cases, research of WOM has been done by focusing famous brands or known products. This research is unique because the author focuses on the counterfeit products.

Although counterfeit market has grown worldwide, research on WOM advertisement for counterfeit remains scarce. In order to fill this void, this paper aimed to investigate the role of WOM in counterfeiting for several reasons.

First, based on previous question mentioned in the introduction part of this paper, the authors found that WOM has significant role in locating counterfeit products. Whether counterfeit products are sold at street vendors, night markets, general shops or internet auction sites, most of customers receive information from their very close acquaintances. It also shows people like to talk and spread information in their familiar group.

Second, previous research on counterfeiting identified product price, vendor characteristics, social, cultural, demographics, and psychographic as drivers and moderating consumers intention to purchase counterfeit products. For this study, authors identified WOM as a unique driver that should be included to determine purchase intention. Although we cannot find WOM as main motivator to go for counterfeit brands but we can find that WOM become the main source of information for these 
kinds of products. There are a number of parties who want to put counterfeiting and piracy under control, or even totally terminate it. Unless the problem is understood clearly, the implications for genuine brands are clearly far-reaching. It is therefore important to understand the information channels of counterfeit brands. Once we discover how people think, react, speak and refer these products, it will help strategy maker to come with some effective majors to overcome the problem of counterfeiting.

Third, purchase probability (in the direction indicated by the WOM) is limited by the Pre purchase probability, which could favor the impact of either PWOM or NWOM. East et al. (2008) discovered that PWOM has more impact than NWOM for brand purchase probability. Similarly, for counterfeit brand, PWOM has more impact than NWOM. It shows consumers perceive PWOM more reliable together with price priority. It also indicates that a place where there is more PWOM than NWOM for counterfeit brand, customer will go for counterfeits. We know that negative publicity is expected due to its low quality and negative acceptance in society. This might be the reason that NWOM has less impact on consumer. Understanding that PWOM is more effective than NWOM can help policy makers or managers of international brands to understand this trend and implement best strategy to discourage consumption of counterfeits and protect the original brand.

At last, the customer who has bought counterfeit has more favorable attitudes when compared to those who have not. This is a real threat for the original brands, because once consumers experiment the counterfeit, they tend to have a favorable attitude and then have a positive behavioral intentions (Matos, Ituassu, \& Rossi 2007). It is also connected with the ethical issues. In this case marketers should try to influence consumer personality, such as integrity, although this is the most difficult to change, encouraging consumers to consider values as responsibility and honesty in their life.

\section{Limitation and Further Research}

\section{Limitation}

This research was conducted with a sample of undergraduate and graduate students of National Taiwan University of Science and Technology in Taiwan, common people walking in mobile shops in New Delhi and some of the author's online friends. There is little reason to believe that the relations of students' behavioral responses to the functions served by their attitudes, including the extent to which they rely on their moral beliefs, will differ significantly from other relevant population. Although this sample frame helped control for some factors, it does not provide the ability to extrapolate to other populations. Counterfeiting is a worldwide problem. Survey with more divergent societies and countries might have been taken to understand complete role of WOM among people of diverse attitude.

Despite the interesting findings, this study has taken into consideration of only two product category i.e. counterfeit bangs and counterfeit mobile phones. There are many categories of brands such as watches, camera, clothes etc. that has been counterfeited. Respondents may have bought a counterfeit product that is not mentioned in the survey questionnaire. Once we take more products category in consideration, people opinion and referral may change and may have different impact.

The other possible limitation is the fact that the result might alter if author have adopted different methodology or different sample size. Considering, for example, that studies come from different sources, such as dissertations and papers published in journals of different quality, decisions related to design, data collection, and analyses could have an influence on the obtained results. Unfortunately, these factors are difficult, if not impossible, to control in the context of role of WOM in counterfeiting.

\section{Future Research Direction}

Future research should further discover the role of WOM in counterfeiting by integrating the prospective of the WOM recipient and WOM giver. An extension to this approach could include variables such as source credibility, source attractiveness, message congruence, message repetition, situational involvement of the recipient and risk perceived by the recipient. These variables should be relevant in understanding how the received WOM influences customers' propensity to pass the information to others about counterfeit products.

Another aspect worthy of future investigation in the affective mechanisms related to the situations in which customer provide either positive or negative WOM based on their personal attitudes towards counterfeits. Correspondingly, future investigations about WOM and its relationship with counterfeits satisfaction and loyalty could be extended to include specific emotions such as anger, regret, frustration, in order to understand the likely emotional and behavioral aspect of negative WOM when compared to the more cognitive positive WOM.

Future research can also try to examine buying behavior based on referral regarding counterfeits products that have various degrees of involvement in more than two countries.

\section{Acknowledgements}

The authors would like to thank the anonymous referees for your valuable comments and suggestions, and the corresponding author Fangyi Liu can be contacted at: fion@ccms.nkfust.edu.tw.

\section{REFERENCES}

Arndt, J. (1967). Role of product-Related conversations in the diffusion of a new product. Journal of Marketing Research, 4, 291-295. doi: $10.2307 / 3149462$

Ashdown, B. K., Gibbons, J. L., Hackathorn, J., \& Harvey D. R. (2011). The influence of social and individual variables on ethnic attitudes in Guatemala. Psychology, 2, 78-84. doi:10.4236/psych.2011.22013

Bansal, H. S., \& Voyer, P. A. (2000). Word-of-mouth processes within a services purchase decision context. Journal of Service Research, 3, 166-177. doi:10.1177/109467050032005

Bolfing, C. P. (1989). How do customers express dissatisfaction and what can service marketers do about it? Journal of Services Marketing, 3, 5-23.

Bone, P. F. (1992). Determinants of word-of-mouth communications during product consumption. Advances in Consumer Research, 19, 579-583.

Buttle, F. A. (1998). Word of mouth: Understanding and managing referral marketing. Journal of Strategic Marketing, 6, 241-254. doi:10.1080/096525498346658

Chang, W. C., Osman, M. M., Tong, E. M. W., \& Tan, D. (2011). Selfconstrual and subjective wellbeing in two ethnic communities in Singapore. Psychology, 2, 63-70. doi:10.4236/psych.2011.22011

Chaudhry, P., Cordell, V., \& Zimmerman, A. (2005). Modeling anticounterfeiting strategies in response to protecting intellectual prop- 
erty rights in a global environment. Marketing Review, 5, 59-72. doi:10.1362/1469347053294832

Cordell, V., Wongtada, N., \& JrKieschnick, R. L. (1996). Counterfeit purchase intentions: Role of lawfulness attitudes and product traits as determinants. Journal of Business Research, 35, 41-53. doi:10.1016/0148-2963(95)00009-7

Desatnick, R. L. (1987). Managing to keep the customer. San Francisco, CA: Jossey-Bass.

East, R., Hammond, K., \& Lomax, W. (2008). Measuring the impact of positive and negative word of mouth on brand purchase probability. International Journal of Research in Marketing, 25, 215-224. doi:10.1016/j.ijresmar.2008.04.001

Eisend, M., \& Schuchert-Guler, P. (2006). Explaining counterfeit purchases: A review and preview. Academy of Marketing Science Review, 12, 1-22.

Engel, J. F., Kegerris, R. J., \& Blackwell, R. D.(1969). Word of mouth communication by the innovator. Journal of Marketing, 33, 15-19. doi:10.2307/1248475

Fang, C. H., Lin, T. M. Y., Liu, F., \& Lin, Y. H. (2011). Product type and word of mouth: A dyadic perspective. Journal of Research in Interactive Marketing, 5, 189-202. doi:10.1108/17505931111187802

Gentry, J. W., Putrevu, S., \& Clifford Shultz II (2006). The effects of counterfeiting on consumer search. Journal of Consumer Behavior, 5, 245-256. doi:10.1002/cb.176

Godes, D., \& Mayzlin, D. (2004). Using online conversations to study word of mouth communication. Marketing Science, 23, 545-560. doi:10.1287/mksc.1040.0071

Gombeski, W. R., Fay, G. W, Niedzielski, K. R., \& Weaver, F. J. (1988). Evaluating promotional strategy effectiveness for a health care organization. Journal of Business Research, 17, 81-90.

doi:10.1016/0148-2963(88)90025-2

Gould, S. J. (1989). Service opinion leadership: A management tool for service providers and product marketers Alike. Journal of Professional Services Marketing, 4, 3-14. doi:10.1300/J090v04n01_02

Grossman, G., \& Shapiro, C. (1988). Foreign counterfeiting of status goods. Quarterly Journal of Economics, 103, 79-100. doi:10.2307/1882643

Grossman, G. M., \& Shapiro C. (1988). Counterfeit-Product trade. American Economic Review, 78, 59-75.

Hartline, M. D., \& Jones, K. C. (1996). Employee performance cues in a hotel service environment: Influence on perceived service quality, value and word of mouth intentions. Journal of Business Research, 35, 207-215. doi:10.1016/0148-2963(95)00126-3

Hovland, C. I., Harvey, O. J., \& Sherif, M. (1957). Assimilation and contrast effects in reactions to communication and attitude change. Journal of Abnormal and Social Psychology, 55, 244-252. doi:10.1037/h0048480

Johnson, J. D., \& Meischke, S. F. (1991). Cancer Information: Women's Source and Content Preferences. Journal of Health Care Marketing, 11, 37-44.

Katz, D. (1960). The functional approach to the study of attitudes. Public Opinion Quarterly, 24, 163-204. doi:10.1086/266945

Katz, E., \& Lazarsfeld, F. P. (1955). Personal influence; the part played by people in the flow of mass communications. Glencoe, IL: The Free Press.

Kay, H. (1990). Fake’s progress. Management Today, 54-59.

Kotler, P., \& Bloom, P. H. (1984). Marketing professional services. Engelwood Cliffs, NJ: Prentice-Hall.

Kenneth, G. D. B. (1985). Appeals to image and claims about quality: Understanding the psychology of advertising. Journal of Personality and Social Psychology, 49, 586-597. doi:10.1037/0022-3514.49.3.586
King, K. W., \& Tinkhan, S. F. (1990). The learning and retention of outdoor advertising. Journal of Advertising Research, 29, 47-51.

Lai, K. K., \& Zaichkowsky J. L. (1999). Brand imitation: Do the chinese have different views? Asia Pacific Journal of Management, 16, 179-192. doi:10.1023/A:1015482707900

Lazarsfeld, P., Berelson, B., \& Gaudet, H. (1948). The people’s choice. New York: Columbia University Press.

Leisen, B., \& Alexander, N. (2001). Combating product counterfeiting: an investigation into the likely effectiveness of a demand-oriented approach. In R. Krishnan, \& M. Viswanathan (Eds.), AMA Winter Educators' Conference Proceedings (Vol. 12, pp. 271-277), Chicago: American Marketing Association.

Matos, C. A., Ituassu, C. T., \& Rossi, C. A. V. (2007). Consumer attitudes towards counterfeits: A review and extension. Journal of Consumer Marketing, 24, 36-47. doi:10.1108/07363760710720975

McDonald, G., \& Roberts, C. (1994). Product piracy: The problem that will not go away. Journal of Product and Brand Management, 3, 55-65. doi:10.1108/10610429410073129

Murray, K. B. (1991). A test of services marketing theory: Consumer information acquisition activities. Journal of Marketing, 55, 10-25. doi: $10.2307 / 1252200$

Peters, A., \& Rowat, W. C. (2011). Associations between dispositional humility and social relationship quality. Psychology, 2, 155-161. doi:10.4236/psych.2011.23025

Penz, E., \& Stottinger, B. (2005). Forget the "real” thing: Take the copy! An explanatory model for the volitional purchase of counterfeit products. In G. Menon, \& A. R. Rao (Eds.), Advances in consumer research (Vol. 32, pp. 568-575). Duluth, MN: Association for Consumer Research.

Rabaglietti, E., Liubicich, M. E., \& Ciairano, S (2011). Gender differences in the relationships between physical activity and the psychological and physical self-reported condition of the elderly in a residential care facility. Psychology, 2, 35-41. doi:10.4236/psych.2011.21006

Richins, M. L. (1983). Negative word-of-mouth by dissatisfied customers: A pilot study. Journal of Marketing, 47, 68-78. doi: $10.2307 / 3203428$

Sen, S. (2009). Why do consumers buy counterfeit luxury brands? Journal of Marketing Research, 46, 247-259. doi:10.1509/jmkr.46.2.247

Snyder, M. (1974). The self-monitoring of expressive behavior. Journal of Personality and Social Psychology, 30, 526-537. doi:10.1037/h0037039

Strandvik, T. (1994). Tolerance zones in perceived service quality. Helsinki: Swedish School of Economics and Business Administration.

Thomas, D. (2007). Terror's purse strings. The New York Times, 30 August 2007, A23-A23.

Tybout, A. M., Calder, B. J., \& Sternthal, B. (1981). Using information processing theory to design marketing strategies. Journal of Marketing Research, 18, 73-79. doi:10.2307/3151315

Villanueva, J., Shijin, Y., \& Dominique, M. H. (2008). The impact of marketing-induced versus word-of-mouth customer acquisition on customer equity growth. Journal of Marketing Research, 45, 48-59. doi:10.1509/jmkr.45.1.48

Westbrook, R. A. (1987). Product/consumption based affective responses and post-purchase processes. Journal of Marketing Research, 24, 258-270. doi:10.2307/3151636

Wilcox, K., Kim, H. M., \& Sen, S. (2009). Why do consumers buy counterfeit luxury brands? Journal of Marketing Research, 46, 247259. doi:10.1509/jmkr.46.2.247

Wilke, R. (1999). Brand imitation and its effects on innovation, competition, and brand equity. Business Horizons, 42, 9-18. doi:10.1016/S0007-6813(99)80033-0 